\title{
Assay of Human Growth Hormone in Pregnancy at Parturition and in Lactation
}

\author{
Detection of a Growth-hormone-like Substance from the Placenta
}

F. C. GREENWOOD*, M.SC., PH.D., W. M. HUNTER*, B.SC., A. KLOPPER†, M.B., CH.B., B.SC., PH.D., M.R.C.o.G.

Brit. med. F., 1964, 1, 22-24

The metabolic and growth changes associated with pregnancy have stimulated interest in the assay of human growth hormone during pregnancy. Until recently no suitable method for the assay of this hormone in the circulation of normal subjects has been available. Methods, reported to be specific for human growth hormone and sensitive enough to give reliable estimates of the concentration of this hormone in the plasma of normal adults, have now been developed (Hunter and Greenwood, 1962, 1964b ; Glick, Roth, Yalow, and Berson, 1963). The importance of the timing of plasma samples for human growth-hormone assay in relation to meals (Greenwood, Hunter, and Marrian, 1964) and to changes in the level of blood sugar (Roth, Glick, Yalow, and Berson, 1963a, 1963b; Hunter and Greenwood, 1964a) has recently been shown.

Preliminary studies of the growth-hormone concentration in maternal and neonatal plasma at delivery showed that abnormally high levels of the hormone were present at that time (Hunter and Greenwood, 1962). The results reported here show that the levels of human growth hormone are above normal in lactation, markedly elevated in the foetus, and may be high throughout pregnancy. The assay has detected an additional factor in the maternal circulation during pregnancy and in the placenta at term which is immunologically similar to pituitary growth hormone. This appears to be identical with a human placental lactogen reported by Josimovich and Maclaren (1962) and by Josimovich, Atwood, and Goss (1963).

\section{Methods}

"Growth hormone" refers to human pituitary growth hormone and the reference standard in the assay was a preparation (I.C.R.F., Batch 3) from acetone-dried pituitaries by the method of Raben (1959).

Subjects.-Six primigravidae and one multipara were studied throughout pregnancy and the puerperium. Patients were rested on a couch for 15 minutes, one hour after a light non-fatty meal. Blood (20 ml.) was drawn from an antecubital vein at the same time of day on each occasion, specimens being taken every four weeks from 12 weeks' gestation until term, an the fourth day of the puerperium, and again six weeks after delivery. Additional specimens were also taken from healthy volunteers in very early pregnancy and in the puerperium. In the latter case both lactating and non-lactating women were used.

After venepuncture the heparinized blood was immediately centrifuged and the plasma frozen in a carbon-dioxide-snowethanol mixture. It was stored at $-20^{\circ} \mathrm{C}$. and transported in vacuum flasks packed with carbon dioxide snow.

\section{Assay of Human Growth Hormone in Plasma}

The radio-immunoelectrophoretic method of Hunter and Greenwood (1962) was used. Heparinized plasma (0.05-0.4 ml.) at dilutions from $1 / 4$ to $1 / 4,000$ or placental extracts were incubated for five days with rabbit anti-human growth hormone serum and ${ }^{131}$ I-labelled human growth hormone. The percentage of ${ }^{131} \mathrm{I}$-labelled human growth hormone bound to immune $\gamma$-globulin from the rabbit antiserum was then determined by electrophoresis and radioactivity measurements. Known amounts of unlabelled human growth hormone were incubated under the same conditions with the same concentrations of antiserum and labelled hormone and a "standard" curve of growth hormone versus radioactivity was constructed. Values for human growth hormone in plasma obtained by reference to this curve were expressed as $\mu \mathrm{mg} . / \mathrm{ml}$. plasma. Full experimental details and an analysis of the reliability of this method are presented elsewhere (Hunter and Greenwood. 1964b).

\section{Determination of the Slope of the Inhibition Curve}

The assay is based upon the specific immunological reaction between ${ }^{131}$ I-labelled human growth hormone and an antiserum to human growth hormone and its progressive inhibition by the addition of increasing amounts of unlabelled human growth hormone. The reaction mixture, ${ }^{131} \mathrm{I}$-labelled growth hormone and ${ }^{131}$ I-labelled growth hormone bound to the immune $\gamma$-globulin of the antiserum, is then resolved by electrophoresis and the radioactivity determined. The degree of inhibition is expressed as a fall in the percentage of ${ }^{131} \mathrm{I}$-labelled growth hormone bound-that is, reacted with the immune $\gamma$-globulin of the antiserum. The inhibition curve is plotted as the percentage ${ }^{131} \mathrm{I}$-label bound against the known amounts of growth hormone added, and is linear when a logarithmic scale is used for the latter. An example of such a curve is shown in Fig. 1. The slope of this curve is a characteristic of the specific immunological reaction between human pituitary growth hormone and its antibody. We have found it convenient to express the curve numerically as a percentage fall in ${ }^{13}{ }^{1} \mathrm{I}-$ labelled growth hormone bound for doubling amounts of growth hormone. This gives a fall of $11.4 \% \pm 2.8 \%$ from one point to the next over the range of growth hormone we were measuring. This slope is taken as $100 \%$ for the purposes of this communication.

If instead of known amounts of unlabelled growth hormone doubling amounts of plasma from non-pregnant subjects are used in the reaction, an inhibition curve parallel to that of the known hormone is obtained-that is, is equal to $100 \%$ of the slope. Reactions identical with that given by human growth hormone have been obtained with plasma from acromegalic, adolescent, and normal subjects. Identical reactions were also given by extracts of human and monkey pituitary glands and by plasma from non-pregnant monkeys. It may be noted that monkey growth hormone has been shown to cross-react completely with antibody raised against human growth hormone (Grumbach and Kaplan, 1962). On the other hand, human

- Scientific Staff, Imperial Cancer Research Fund, London.

$\dagger$ Scientific Staff, Medical Research Council, Obstetric Medicine Research Unit, Aberdeen. 
chorionic gonadotrophin did not react with antisera to human growth hormone and its presence did not interfere with the assay of the latter (Hunter and Greenwood, 1964b).

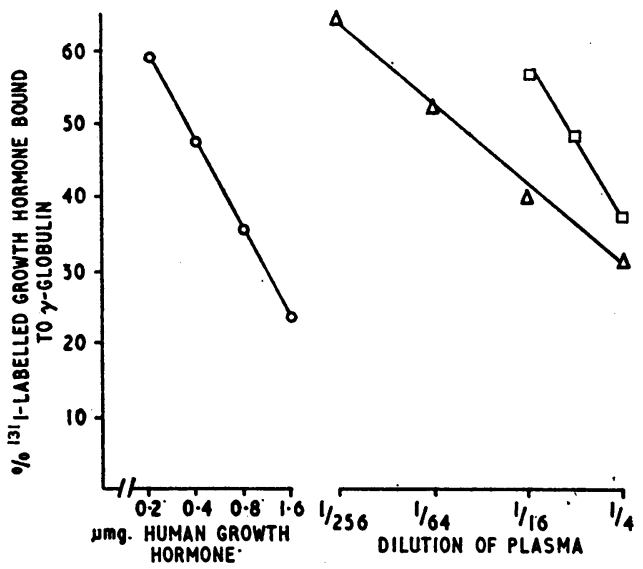

FIG. 1.-Inhibition of the reaction between ${ }^{131} \mathrm{I}$ labelled growth hormone and antiserum to growth hormone. The inhibition or standard curve for unlabelled growth hormone is shown (O). Plasma $(0.4 \mathrm{ml})$ from a pregnant woman $(\Delta)$ and a woman in lactation $(\square)$ were assayed at the dilutions given.

\section{Preparation of Placental Extracts}

Fresh placentae at term were transported on ice in vacuum flasks, cut into strips, rinsed in isotonic saline, and homogenized in a blender. The homogenate was lyophilized and the powder stored. Batches of the powder $(50 \mathrm{~g}$.) were extracted by the method devised by Raben (1959) for the purification of pituitary growth hormone. Yields from $50 \mathrm{~g}$. of the placental powder varied from 40 to $200 \mathrm{mg}$. An extract from a single monkey placenta stored at $-20^{\circ} \mathrm{C}$. was obtained by the same method.

\section{Results}

\section{Detection of Cross-reacting Substance During Pregnancy and in Placentae at Term}

Parallelism between the inhibition curves given by standard growth hormone and a plasma sample provides evidence that the plasma contains pituitary growth hormone or a protein which is immunologically identical to it. The slope of inhibition curves from 30 samples of human plasma during pregnancy was not parallel with that obtained from standard human growth hormone. These slopes varied from $30 \%$ to $85 \%$ of the human-growth-hormone slope. A single example is shown in Fig. 1. The reduced slope suggested the presence of a substance, not growth hormone, but capable of some degree of cross-reaction with antibodies to it. The change in slope given by serial samples of plasma during pregnancy from one patient is shown in Fig. 2. It was inferred that in middle and late pregnancy two components occur, the one being growth hormone and the other an unknown material immunologically similar to pituitary growth hormone. The variation of the slope seen with different samples of pregnancy plasma suggested that the ratio of the amounts of the two components varies during pregnancy. A depression of the slope of standard growth hormone was obtained by adding varying amounts of an extract obtained from placentae to growth hormone $(0.02$ to $20 \mu \mathrm{g}$.). On purification a fraction was obtained which gave by itself a slope of $30 \%$ of that given by growth hormone when incubated in doubling amounts from 0.3 to $20 \mu \mathrm{mg}$. with antiserum to growth hormone and ${ }^{131}$ I-labelled growth hormone. Extracts of monkey placentae yielded similar results.

The slopes of the inhibition curve obtained from serial assays during pregnancy (Fig. 2) showed that at eight weeks this subject had a slope within the experimental range for growth hormone and suggested that growth hormone alone was present at that time. A valid estimate of the amount of growth hormone was therefore possible and a value of $20 \mu \mathrm{mg} . / \mathrm{ml}$. was obtained. This is much higher than the values found in the plasma of non-pregnant women. By the ninth week, however, a reduced slope ( $80 \%$ of the growth hormone slope) was found, suggesting the appearance of the second component immunologically similar to growth hormone. The measurements of growth hormone in pregnant subjects after the ninth week are therefore not valid.

It may be noted that one subject accepted for serial study throughout pregnancy had a spontaneous abortion one week after her initial sample at 12 weeks was taken. No growth hormone or cross-reacting substance was found in this specimen.

\section{Detection of the Cross-reacting Component at Parturition: its Absence in the Foetus and in Lactation}

At delivery the cross-reacting substance is still present in the mother's circulation, but not in that of her baby. This can be seen in the Table, which lists the slope and assay values found in maternal peripheral venous blood and mixed arterial and venous blood from the umbilical vessels of the baby. Values from a patient at elective caesarean section for ccstracted pelvis are also shown in the Table. These findings suggest that crossreacting material is present in the blood of the uterine veins and in retroplacental maternal blood. The inhibition curves obtained from plasma from the arteries or veins of the umbilical cord or from liquor amnii are parallel to that given by growth hormone (Fig. 3) and suggest that growth hormone only is

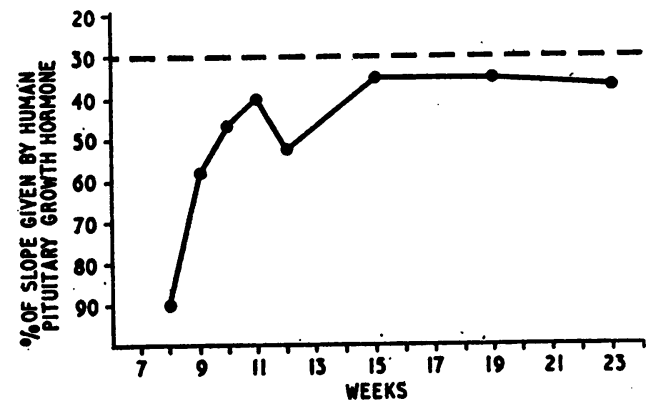

FIG. 2.-Appearance of a protein cross-reacting with antiserum to growth hormone in pregnancy. Plasma samples from a pregnant woman were assayed at $0.4 \mathrm{ml}$. each of $1 / 256,1 / 64,1 / 16$, and $1 / 4$ dilutions. The slope of the inhibition curve thus obtained is expressed as a percentage of the slope of the inhibition curve given by growth hormone (O). The slope of the inhibition curve given by a placental extract is shown as a broken line.

Detection of Cross-reacting Substance During and After Parturition in Plasma Assayed for Growth Hormone

Plasma was assayed for growth hormone at three or more dilutions and the slope Plasma was assayed for growth hormone at three or more dilutions and the slope
of the inhibition obtained. This is expressed as a percentage of the slope given by growth hormone. Where the slope was identical with growth hormone (100) values
of growth hormone in the plasma are shown, expressed as $\mu \mathrm{mg}$./ml. plasma. The number of assays are given in parentheses.

\begin{tabular}{|c|c|c|c|}
\hline \multicolumn{2}{|c|}{ Plasma Assayed } & $\begin{array}{l}\text { Slope of the } \\
\text { Inhibition Curve }\end{array}$ & $\begin{array}{l}\text { Level of } \\
\text { Growth Hormone }\end{array}$ \\
\hline $\begin{array}{l}\text { Maternal, peripheral (6) } \\
\text { Uterine venous (1) } \\
\text { Retroplacental (1) } \\
\text { Umbilical (10) } \\
\text { Foetal, arterial (1) } \\
\text { Foetal, venous (1) } \\
\text { ", } \\
\text { Maternal, "peripheral* } \\
\text { partum) (11) } \\
\begin{array}{c}\text { Maternal, peripheral } \\
\text { partum) (1) .. }\end{array}\end{array}$ & 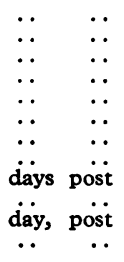 & $\begin{array}{c}+68 \pm 6 \cdot 4 \\
38 \\
23 \\
100 \\
100 \\
100 \\
100 \\
100 \\
100 \\
48\end{array}$ & $\begin{array}{c}\bar{Z} \\
\overline{\bar{a}} \\
+49 \cdot 7 \pm 57 \cdot 8 \\
23 \cdot 0 \\
73 \cdot 0 \\
23 \cdot 3 \\
60 \cdot 0 \\
+4 \cdot 5 \pm 2 \cdot 1 \\
-\end{array}$ \\
\hline
\end{tabular}

* Lactation suppressed in 2 patients. † Mean \pm S.D. 
present. The levels of growth hormone measured in the foetus are high, approximately $50 \mu \mathrm{mg} . / \mathrm{ml}$. and are somewhat higher in liquor amnii $(123 \mu \mathrm{mg} . / \mathrm{ml}$.)

We have attempted to study the disappearance of crossreacting substance from the circulation. The Table shows that in one woman a slope value indicative of the presence of crossreacting substance was found on the second day of the puerperium, but in 11 others no cross-reacting substance was found two to eight days post partum. The average growthhormone level of these 11 subjects which gave valid assays was $4.5 \mu \mathrm{mg} . / \mathrm{ml}$., a value much lower than the $20 \mu \mathrm{mg} . / \mathrm{ml}$. found in the only valid assay in early pregnancy and higher than nonpregnant subjects.

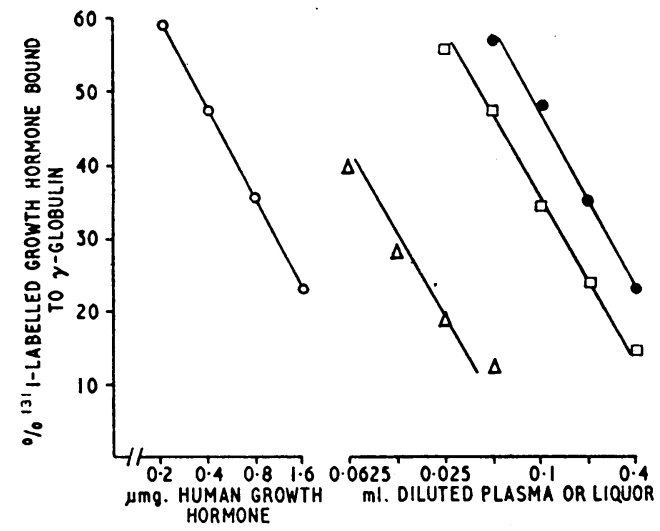

FIG. 3.-Inhibition of the reaction between ${ }^{231} \mathrm{I}$ labelled growth hormone and antiserum to growth hormone. The inhibition or standard curve for unlabelled growth hormone is shown (O). Liquor amnii (diluted $1 / 4)(\triangle)$, plasma from the foetal vein (diluted 1/8) ( $\square$ ), and plasma from the foetal artery (diluted $1 / 16$ ) (O) were assayed in the amounts given.

\section{Results Obtained in Non-pregnant Subjects}

In 500 or so plasma samples from non-pregnant subjects sssayed for growth hormone, the cross-reacting substance was detected in only two instances. The first was an adolescent girl of 14 with epilepsy who had slopes of $55 \%$ and $49 \%$ at a tive-months interval. Amenorrhoea had occurred shortly before the first sample and persisted until after the second sample. There was no evidence of pregnancy. The second instance sccurred in a 45-year-old man with a 10-year history of acromegaly. No explanation of these findings can be offered at present.

\section{Discussion}

Our findings suggest that during pregnancy high levels of growth hormone are found in the foetus and that the concentration of growth hormone in the maternal circulation may also be raised. In addition, a second factor immunologically similar but not identical to growth hormone appears in the maternal circulation during pregnancy but does not occur in the foetus. The high concentration of this material in the retroplacental blood and in the uterine veins indicated the possibility that it derives from the placenta. We have been able to extract from human placentae a substance having the immunological characteristics of this material. A number of immunological observations similar to ours have already been reported by Josimovich and Maclaren (1962). In addition, the placental extract was shown to possess lactogenic and luteotrophic properties but no growth hormonal activity in experimental animals (Josimovich, Atwood, and Goss, 1963). It is apparent that both groups are dealing with the same substance, possibly a hitherto unknown hormone of the placenta into the maternal circulation. Its function in pregnancy is not known.

It would be of interest to study the secretion of this material more closely, and we are trying to devise means for its quantitative assay in pregnancy blood. The fact that it appears to be of placental origin but does not occur in the foetal circulation indicates that it may derive from the maternal part of the placenta. It is notable that in simultaneous assays of growth hormone in umbilical arteries and vein the same high concentration of growth hormone was found in both sets of vessels. This would accord with the view that foetal growth hormone does not derive from the placenta and fits in with the general findings that the foetal pituitary is an actively functioning organ.

\section{Summary}

A new technique for the assay of human growth hormone has been applied to the study of this substance in pregnancy. High levels of hormone occur in the foetus and probably in early pregnancy in the mother. Assays in later pregnancy were invalidated by a cross-reacting substance of placental origin, immunologically similar to human growth hormone and reported to possess lactogenic hormone activity.

We wish to thank Dr. G. F. Marrian, F.R.S., for his encouragement of this work. The valuable technical assistance of Miss C. Harris and Mrs. H. Coats is gratefully acknowledged.

\section{REFERENCES}

Glick, S. M., Roth, J., Yalow, R. S., and Berson, S. A. (1963). Nature (Lond.), 199, 784.

Greenwood, F. C., Hunter, W. M., and Marrian, V. J. (1964). Brit. med 7., 1,25 .

Grumbach, M. M., and Kaplan, S. L. (1962). Ciba Found. Coll. Endocr., 14, 63.

Hunter, W. M., and Greenwood, F. C. (1962). Biochem. Y., 85, 39P.

(1964a). To be published.

Josimovich, J. B., Atwood, B. L., and Goss, D. A. (1963). Endocrinotogy. 73,410 .

- and Maclaren, J. A. (1962). Ibid., 71, 209.

Raben, M. S. (1959). Recent Progr. Hormone Res., 15, 71.

Roth, J., Glick, S. M., Yalow, R. S., and Berson, S. A. (1963a). Science. $140,987$. 